\title{
OS IMPACTOS DA PANDEMIA COVID-19 NOS CONTRATOS DE ASSISTÊNCIA SUPLEMENTAR À SAÚDE: A PROTEÇÃO DOS USUÁRIOS COM ESTEIO NO MICROSSISTEMA CONSUMERISTA.
}

\author{
Ana Clara Suzart Lopes da Silva ${ }^{1}$ \\ Joseane Suzart Lopes da Silva ${ }^{2}$
}

RESUMO: A pandemia do Coronavírus tem acarretado adversos impactos no âmbito das relações de consumo, razão pela qual objetiva-se, no presente artigo, analisar os principais impactos no que concerne aos contratos de assistência suplementar à saúde. A hipótese central prevista consiste na ausência de efetivas providências para a proteção dos interesses e os direitos dos usuários dos planos de saúde. Conclui-se que os entes, que integram o Sistema Nacional de Defesa do Consumidor (SNDC), devem interagir de modo a evitar e a combater práticas abusivas que venham a ser concretizadas em desfavor dos vulneráveis, mormente quando atingem o direito à saúde.

PALAVRAS-CHAVE: pandemia covid-19; saúde suplementar; consumidores; proteção.

\section{THE IMPACTS OF THE COVID-19 PANDEMIC ON SUPPLEMENTARY HEALTH CARE CONTRACTS: THE USERS PROTECTION BASED ON THE CONSUMER MICROSYSTEM.}

\begin{abstract}
The Coronavirus pandemic has had adverse impacts on consumer relations, which is why the purpose of this article is to analyze the main impacts with regard to supplementary health care contracts. The central hypothesis envisaged is the absence of effective measures to protect the interests and rights of users of health plans. It is concluded that the entities, which are part of the National Consumer Protection System (SNDC), must interact in order to prevent and combat abusive practices that may be implemented to the disadvantage of the vulnerable, especially when they reach the right to health.
\end{abstract}

KEYWORDS: coronavirus pandemic; supplementary health; consumers; protection.

\footnotetext{
${ }^{1}$ Advogada. Bachalera em Direito pela Universidade Federal da Bahia. Mestre em Direito pela Universidade Federal da Bahia. Especialista em Direito Processual Civil pela Faculdade Baiana de Direito. Associada Honorífica e Diretora Jurídica da Associação Baiana de Defesa do Consumidor - ABDECON. E-mail: anaclarasuzart@ hotmail.com.

${ }^{2}$ Mestre e Doutora em Direito pela Universidade Federal da Bahia. Membro do Ministério Público da Bahia, desde 1995, titularizando a $5^{\text {a }}$ Promotoria de Justiça do Consumidor da Capital. Professora de Direito das Relações de Consumo da Universidade Federal da Bahia. Professora da Pós-Graduação em Direito Civil da Faculdade Baiana. Coordenadora Científica da Associação Baiana de Defesa do Consumidor - ABDECON. Diretora do Instituto Brasileiro de Política e Direito do Consumidor (BRASILCON) para a Região Nordeste. Membro do Centro de Estudos Europeus e Alemães da UFRGS e da PUCRS. Membro da Rede de Pesquisa em Direito Civil Contemporâneo. Integrante do Comitê de Orientação Editorial das Revistas de Direito do Consumidor (RDC), de Direito Civil Contemporâneo (RDCC) e dos Tribunais (RT). Pós-Doutoranda pela Faculdade de Direito da Universidade de Coimbra. E-mail: joseane.suzart@outlook.com.
} 


\section{INTRODUÇÃO}

A COVID-19 é uma moléstia decorrente da variação da família coronavírus, responsável por causar infecções respiratórias. A Organização Mundial de Saúde emitiu o primeiro alerta para doença em 31 de dezembro de 2019, após autoridades chinesas notificarem casos de uma misteriosa pneumonia na cidade de Wuhan, metrópole chinesa com 11 milhões de habitantes. Os casos começaram como um surto neste local e progrediram, tornando-se uma epidemia, que se espalhou por toda a China. Dado o grau de avanço dos casos de contaminação pelo novo coronavírus, especialmente no território chinês, a OMS decretou, em 30 de janeiro de 2020, Emergência de Saúde Pública de Importância Internacional (ESPII) - o mais alto nível de alerta da Organização. A posteriori, diante do alastramento do vírus por todo o mundo, declarou a pandemia do COVID-19, considerando que existiam àquela época mais de 118 mil casos em 114 países e 4,2 mil óbitos.

No Brasil, desde 03 de fevereiro de 2020, por meio da Portaria n. ${ }^{\circ} 188$ do Ministério da Saúde, foi estabelecido o Estado de Emergência de Saúde Pública de Importância Nacional (ESPIN), em decorrência da infecção humana pelo novo coronavírus, justamente com o emprego urgente de medidas de prevenção, controle e contenção de riscos, danos e agravos à incolumidade pública. No dia 26 de fevereiro, foi confirmado o primeiro caso da doença no Brasil, referente a um indivíduo, com histórico de viagem para a Itália, especificamente na região da Lombardia. Desse modo, o vírus começou a se espalhar pelo território brasileiro e, no dia 20 de março, o Ministério da Saúde noticiou a transmissão comunitária nacional, de modo que os gestores nacionais passaram a ser orientados a adotar medidas "não farmacológicas", para promover o distanciamento social e evitar aglomerações. Desse modo, torna imprescindível analisar os impactos desta pandemia no âmbito das relações de consumo.

A pandemia gerada pelo novo coronavírus tem acarretado adversos impactos no âmbito das relações de consumo, razão pela qual objetiva-se, no presente artigo, analisar os principais impactos no que concerne aos contratos de assistência suplementar à saúde, que tratam de bens de inquebrantável importância para a população. A hipótese central prevista consiste na ausência de efetivas providências para a proteção dos interesses e os direitos dos usuários dos planos de saúde. Na primeira parte desta exposição, serão tecidas considerações sobre o cenário estigmatizado pela COVID-19, transpondo-a, em seguida, para os aspectos gerais acerca dos planos de saúde. Serão examinadas a cobertura obrigatória do exame 
destinado à detecção da moléstia, assim como a flexibilização das regras sobre a instituição de operadoras do setor e a utilização de recursos financeiros reservados. A "telessaúde", a prorrogação e a suspensão de prazos para consultas, procedimentos e tratamentos adrede consistirão objeto de análise; do mesmo modo, a questão do reajuste das mensalidades e a responsabilidade civil dos envolvidos na prestação dos serviços.

No que concerne à metodologia, urge explicitar que foram utilizados os métodos dialético e argumentativo. Quanto às linhas metodológicas, seguiu-se a de natureza crítica e dentre os tipos genéricos de investigação, a jurídico-exploratória. Utilizou-se a pesquisa exploratória, bibliográfica e documental. Do ponto de vista da natureza do empreendimento, trata-se de pesquisa aplicada e no pertinente à forma desta, manejou-se a qualitativa. No campo das técnicas, optou-se pela documentação indireta, abrangendo a pesquisa bibliográfica e documental (WITKER, 1985, p. 89; HERRERA, 1998. p. 86).

\section{OS CONTRATOS DE ASSISTÊNCIA SUPLEMENTAR À SAÚDE: VÍNCULOS JURÍDICOS EXISTENCIAIS E DURADOUROS QUE SUSCITAM CUIDADOSA CONCEPÇÃO, INTERPRETAÇÃO E FISCALIZAÇÃO DADO O SEU OBJETO SER O BEM MAIOR.}

O contrato de assistência suplementar à saúde, mesmo celebrado no âmbito privado, leciona Lorenzetti, tem por objetivo a proteção da saúde concebida como um bem fundamental. Desta forma, além de serem qualificados como vínculos de duração extensa, os planos de saúde lidam com o direito essencial dos indivíduos cujo tratamento indevido pode gerar a eliminação da vida - exigindo, portanto, uma rigorosa fiscalização do conteúdo das normas que os guarnecem. Uma relação contratual desse tipo não pode ser tratada como um vínculo comum, razão pela qual o art. $3^{\circ}$, inciso I, do Decreto n. ${ }^{\circ} 10.282 / 20$ qualificou a assistência à saúde como essencial, incluídos os serviços médicos e hospitalares. A prestação de um direito fundamental "pode desequilibrar a lógica contratualista, já que se concedem direitos e ações que seriam impensáveis em um contrato comum” (LORENZETTI, 1998, p. 369).

1.1 CONCEITO E CARACTERÍSTICAS DOS PLANOS DE SAÚDE: LIAMES QUE VERSAM SOBRE O ESTADO VITAL DOS SUJEITOS.

Os planos privados de assistência à saúde, conforme dispõe o art. $1^{1}$, inciso I, da Lei n. ${ }^{\circ}$ 9.656/98, constituem prestações continuadas de serviços ou cobertura de custos assistenciais a preço pré ou pós estabelecido, por prazo indeterminado, com a 
finalidade de garantir, sem limite financeiro, a assistência à saúde dos contratantes, englobando atendimento médico, hospitalar e odontológico. Para a concretização do objeto contratual, as operadoras de planos de saúde podem apresentar aos consumidores uma lista de profissionais e/ou serviços de saúde, configurando-se uma rede credenciada, contratada ou referenciada. Será possível também as empresas do setor facultarem aos contratantes a livre escolha de profissionais e estabelecimentos de saúde que não integrem a dita lista, devendo os mesmos efetivarem os pagamentos devidos, para solicitarem posterior reembolso (GREGORI, 2011).

A partir da análise do conceito dos planos e seguros de saúde, podem ser extraídos elementos fundamentais diferenciando-os das demais figuras contratuais que permeiam o universo jurídico. Pode-se constatar a existência de três fatores essenciais para a instituição de um plano e/ou seguro saúde: o fornecedor, que há sempre de ser uma pessoa jurídica; o consumidor, que firma o contrato e tanto poderá ser o indivíduo isolado ou uma pessoa jurídica que formaliza o liame jurídico em prol de um grupo a ela vinculado, dando origem aos planos de saúde coletivos conforme as tratará a seguir; e um objeto, que há de ser sempre a busca de proteção para a saúde humana. Presentes tais fatores essenciais, as empresas inseridas no mercado de saúde suplementar dispõem da liberdade de adoção de critérios para a formalização dos contratos com os interessados (SILVA, 2009).

Os planos de saúde não são criados para o atendimento de uma necessidade momentânea dos consumidores, uma vez que a prestação continuada constitui uma nota fundamental na caracterização dos contratos advindos. No próximo tópico, inclusive, abordar-se-á tal aspecto, enfatizando-se que a inexistência de um termo final para a conclusão dos contratos de saúde suplementar ensejou uma preocupação mais abalizada do legislador em vista da proteção dos usuários, eis que estes não visam contratar um objeto fugaz ou efêmero, mas sim, assegurar um atendimento à saúde que não tem um lapsus temporis predefinido. A continuidade da relação contratual entre as operadoras e os consumidores decorre da natureza do objeto perseguido: a saúde.

A Lei n. ${ }^{\circ}$ 9.656/98 apresenta cinco planos de assistência à saúde, sendo que toda e qualquer operadora deverá ofertar aos consumidores, quer tenham formalizado contratos antigos ou venham a subscrever os atuais, o plano-referência, ou seja, o mais abrangente e amplo de todos, mas que contém algumas exceções e limitações (BOTTESINI; MACHADO, 
2015). Os planos mínimos ou subplanos são: o ambulatorial; o hospitalar; o hospitalar com obstetrícia; e o odontológico. Os planos mínimos podem ser comercializados de forma agrupada, dando origem a planos mistos. Cada plano de saúde apresenta características específicas que os diferenciam entre si. Contudo, na presente exposição, não serão tratadas as peculiaridades de cada um dos planos de saúde previstos na Lei n. ${ }^{\circ} 9.656 / 98$, em razão de não ser cabível a sua ampliação demasiada.

Outro aspecto a ser salientado é que todo e qualquer instrumento contratual relativo à assistência suplementar à saúde deverá obedecer a certos requisitos mínimos, para poder ser ofertado ao público. O referido contrato deverá indicar a cobertura que o plano efetivará efetivar, expondo a dimensão que esta, por lei, terá que abarcar para não prejudicar os interesses dos consumidores contratantes. A operadora do plano ou seguro de saúde, no contrato formalizado, deve informar, de modo claro e preciso, qual o tipo de serviço que se predispõe a prestar e, principalmente, as limitações existentes.

No que concerne ao regime de contratação, os planos de saúde podem ser individuais e familiares ou coletivos, conforme dispõe a Resolução n. 195/09, editada pela ANS. Os planos individuais podem ser contratados por um sujeito em prol da sua própria pessoa ou do seu núcleo familiar, sendo que, na atualidade, um número exíguo de operadoras oferece tal modalidade (SCAFF, 2010; SCHULMAN, 2009; TRETTEL, 2009). Já os planos coletivos subdividem-se em "empresariais" ou "por adesão", consistindo os primeiros em negócio jurídico firmado por sociedades em benefícios dos seus empregados e dependentes; enquanto os segundos destinam-se às demais pessoas jurídicas que objetivem a prestação de serviços na área da saúde para aqueles que, de alguma forma, estejam vinculados à sua estrutura (SILVA, 2018, p. 217-260).

O direito da presença do acompanhante para os pacientes, crianças, adolescentes e idosos, que estejam em internação hospitalar, encontra-se previsto no art. 12, inciso II, alínea "f" da Lei de Planos de Saúde e no art. 16 do Estatuto de Idoso. No entanto, diante da alta possibilidade de contaminação pelo coronavírus, entende-se que a negativa a tal direito não deve ser considerada prática abusiva. No entanto, aquele que seria acompanhante deve receber informações claras sobre os procedimentos a serem realizados e o estado de saúde do paciente em tratamento, em observância ao art. $6^{\circ}$, inciso III, do CDC e ao art. 34 do Código de Ética Médica. 


\subsection{CARACTERÍSTICAS DOS PLANOS DE SAÚDE: LIAMES QUE VERSAM} SOBRE O ESTADO VITAL DOS SUJEITOS.

Os contratos de planos e seguros de saúde terão uma vigência mínima de 01 (um) ano, sendo, após este lapso de tempo, renovados de forma automática, o que os caracteriza como de execução diferida por prazo indeterminado. Intitulam-se estes contratos "cativos de longa duração", sendo que, em geral, as pessoas os formalizam quando ainda não estão necessitando do uso das coberturas ofertadas, para que posteriormente, quando as doenças aflorem, principalmente em virtude da idade, estejam assistidas.

A expressão "contratos cativos de longa duração" tem sido atribuída, por Cláudia Lima Marques (MARQUES, 2002, p. XI), às relações contratuais que terminam perpassando por um extenso período de tempo, uma vez que, principalmente, para os consumidores, não será interessante que o vínculo finalize após prazo de pequeno decurso. Os planos de saúde são contratos cativos porque os consumidores, normalmente, quando os subscrevem, não podem fazer uso imediato dos serviços disponibilizados, diante dos prazos de carência estipulados. Os usuários contribuem durante certo tempo para uso posterior, e quanto mais o tempo transcorre, intensifica-se a vinculação destes ao plano ou seguro de saúde, dado que, caso partam para uma outra relação contratual, perderão os valores já pagos e terão que se submeter a novo período de carência.

$\mathrm{Na}$ realidade, objetivam os usuários dos planos ou seguros de saúde que a relação seja duradoura, pois pretendem que as suas necessidades sejam atendidas não somente de forma imediata, mas, também, futuramente (MARQUES, 2002, p. 79). A longevidade que se espera dos contratos de planos de saúde conduziu Ronaldo Porto Macedo Júnior a denominá-los de "contratos relacionais" (MACEDO JR., 1998, p. 291). A vulnerabilidade dos consumidores é flagrante diante dos planos de saúde, uma vez que atrelados a estes de forma duradoura - sem a pretensão de findar a relação formalizada, pois busca-se uma proteção futura e o não-desperdício do quanto já pago - terminam aceitando os abusos cometidos. Por tal razão, Cláudia Lima Marques (MARQUES, 2019, p. 394) afirma que constituem "contratos sui generis", devendo ser analisados e interpretados com cautela, para a devida coibição das majorações praticadas. 
Nos contratos de larga duração, a presença de cláusulas abusivas e demais posturas iníquas causam maiores impactos negativos para os consumidores, uma vez que a relação contratual se protrai no tempo e vai sendo maculada com os efeitos nefastos das estipulações indevidas. Diante da singularidade dos contratos duradouros, Ricardo Lorenzetti (LORENZETTI, 1999-2000, p. 119) afirma que nestes não há a previsão material dos bens, mas tão-somente normas procedimentais, já que a evolução tecnológica poderá imprimir modificações na prestação da obrigação. Nos "contratos relacionais", a durabilidade razoável da relação jurídica é um dos fatores fundamentais que os diferenciam dos demais (MACEDO JR., 1998, p. 147-166). Isso significa afirmar que as partes devem estar reunidas, de modo contínuo, para discutirem as condições de execução do contrato.

Nos contratos de longa duração, em geral, deve haver uma preocupação constante com o teor das cláusulas contratuais, e com maior razão, quando tratam de relações jurídicas cujo objeto constitui a saúde das pessoas. Lorenzetti argumenta que o contrato de "medicina prepaga", mesmo celebrado no âmbito privado, tem por objetivo a proteção da saúde concebida como um direito fundamental. Desta forma, além de serem qualificados como contratos de duração extensa, os planos e seguros de saúde lidam com o direito essencial dos indivíduos - cujo tratamento indevido pode gerar a eliminação da vida - exigindo, portanto uma rigorosa fiscalização do conteúdo das normas que os guarnecem (LORENZETTI, 1998, p. 369).

\section{OS REFLEXOS DA COVID-19 PARA AS RELAÇÕES DE CONSUMO: A} SITUAÇÃO dOS PLANOS DE SAÚdE E A PROTEÇÃo DOS USUÁRIOS DIANTE DAS NORMAS QUE ESTÃO SENDO EDITADAS.

O escopo da Lei n. ${ }^{\circ}$ 13.979/20 é a proteção da coletividade no decorrer da situação de emergência de saúde pública, cuja duração será prevista pelo Ministério da Saúde disporá, não podendo ser superior ao declarado pela OMS, conforme dispõem o seu art. $1^{\circ}$ e os parágrafos $1^{\circ}$ e $2^{\circ}$. Foram previstas medidas necessárias para a prevenção e o combate à pandemia que podem ser agrupadas em 03 (três) conjuntos: o afastamento físico dos indivíduos; a realização de investigações e tratamentos em seres humanos; e a utilização e aquisição de bens na modalidade excepcional. No primeiro bloco, encontram-se o isolamento, a quarentena e a restrição do traslado de pessoas; enquanto, no segundo, estão os exames, as vacinas e os tratamentos; e, no derradeiro, as requisições e contratações pelo setor público (SILVA, 2020). 
A saúde suplementar, prevista no art. 199 da Carta Magna, passou a atrair inúmeros consumidores por assegurar valores valiosos, quais sejam: a segurança, a previsibilidade e a proteção contra riscos futuros (MARQUES, 1995, p. 34-77). Desse modo, hodiernamente, inclui cerca de 48 milhões de pessoas, ou seja, cerca de $24 \%$ da população. Torna-se imprescindível, portanto, analisar os impactos da pandemia do COVID-19 na saúde privada. Os direitos básicos contidos no microssistema consumerista jamais poderão ser desprezados (MIRAGEM, 2019, p. 67), não obstante a análise dos fatores econômicos seja relevante, mormente neste momento em que o equilíbrio das relações contratuais urge que seja preservado, evitando-se a desestruturação de empresas e a afetação de milhares de trabalhadores e prestadores de serviços (MARQUES, 2019, p. 101; BENJAMIN, 2017, p. 89).

A Agência Nacional de Saúde Suplementar, após instalação do cenário pandêmico no mundo e no Brasil, vem editando atos expedindo orientações que podem ser reunidas em 05 (cinco) blocos, quais sejam: a obrigatoriedade para que realizem o exame para a identificação da COVID-19; a flexibilização das regras sobre o registro e a acreditação das operadoras; a amenização das exigências relativas à utilização do capital destas; a intitulada Telessaúde; e a ampliação e/ou suspensão de prazos para consultas, procedimentos e tratamentos.

Como será exposto nas linhas subsequentes, vislumbra-se que, até o presente momento, limitou-se a autarquia reguladora a expedir, como determinação protetiva dos consumidores, a compulsória realização da avaliação sobre a moléstia. Nenhuma providência para a intensificação quanto à fiscalização das empresas do setor restou ordenada, mesmo sendo a saúde o bem jurídico mais relevante de todos, sem o qual, não se consegue sobreviver (GHERSI; WEINGARTEN; IPPOLITO, 1999, p. 67). Os contratos coletivos, por adesão ou empresariais, que vêm sendo alvos de constantes rescisões imotivadas, não foi objeto de qualquer medida para se evitar a extinção dos vínculos.

2.1 A PROEMINÊNCIA DA ASSISTÊNCIA SUPLEMENTAR À SAÚDE PARA A MANUTENÇÃO DO ESTADO VITAL DOS SERES HUMANOS: A OBRIGATÓRIA COBERTURA DO EXAME PARA DIAGNOSTICAR A MOLÉSTIA.

A Resolução Normativa n. ${ }^{\circ}$ 453, de 12 de março de 2020, alterou a RN n. ${ }^{\circ}$ 428/17, que dispõe sobre o Rol de Procedimentos e Eventos em Saúde no âmbito da Saúde Suplementar, para regulamentar a utilização de testes diagnósticos para infecção pelo 
Coronavírus, tornando-o obrigatório apenas quando "o paciente se enquadrar na definição de caso suspeito ou provável de doença” (MIRAGEM, 2020, p. 1-9). Como afirma Bruno Miragem, "a exceção feita pela lei aos 'casos de cataclismos, guerras e comoções internas, quando declarados pela autoridade competente' (art. 10, inciso X), não afasta ou restringe a cobertura em questão". Complementa que se tratando da saúde, "é de exigir-se interpretação que preserve a própria causa do contrato, bem como que se interprete restritivamente as exceções à regra geral”. Esta observação doutrinária é válida para o obrigatório cumprimento das coberturas atinentes às modalidades contratuais existentes, inclusive se o plano for ambulatorial, bem como se o paciente estiver ou não internado.

Conforme a Resolução Normativa n. ${ }^{\circ}$ 453/2020 da ANS, o exame de detecção do COVID-19, o SARS-CoV-2 (CORONAVÍRUS COVID-19) - pesquisa por RT - PCR (com diretriz de utilização), foi incluído no Rol de Procedimentos Obrigatórios para beneficiários de planos de saúde, com segmentação ambulatorial, hospitalar ou referência, desde que haja indicação médica, de acordo com o protocolo e as diretrizes definidas pelo Ministério da Saúde. As operadoras de planos de saúde, devem indicar, de forma clara e inteligível, em consonância com o art. $6^{\circ}$, inciso III, do CDC, os locais de atendimento, através dos canais de atendimento da operadora (telefone, e-mail e site), bem como através de cartas e SMS para os consumidores. Além disso, deve prestar informações sobre a doença através dos canais de comunicação com o consumidor.

Os exames devem ser oferecidos no prazo de até 3 dias úteis após a solicitação pelo consumidor, conforme orientação médica, de acordo com a Resolução nº 259/2011 da ANS. A operadora de plano de saúde não pode impor prazo maior sob argumento de autorização de procedimento, pois há previsão na citada Resolução. Insta salientar que não pode se recusar a cobrir exame de paciente, se houver indicação médica, sob pena de incidir no art. 39, inciso II, do CDC. O citado exame pode ser realizado tanto a nível ambulatorial, como com o paciente internado. No entanto, em virtude da enorme demanda, bem como da situação de pandemia e calamidade pública, é possível, na ausência de kits de testagem, restringir os exames para os casos mais graves.

$\mathrm{Na}$ hipótese de ter realizado o exame fora da rede credenciada, o consumidor terá direito ao reembolso, desde que o procedimento esteja previsto no instrumento contratual ou se tiver sido indicado pelo médico em situação de urgência e emergência. As condições de reembolso devem estar previstas no contrato e este deverá ser realizado no prazo de 30 (trinta) 
dias. É importante que o consumidor arquive todos os comprovantes de pagamento e dos atendimentos que efetuar quanto ao pedido de reembolso.

\subsection{A FLEXIBILIZAÇÃO DAS REGRAS PARA A INSTITUIÇÃO DE OPERADORAS DE PLANOS DE SAÚDE E EM FACE DA GESTÃO DE RECURSOS FINANCEIROS: A PREOCUPAÇÃO COM O SURGIMENTO DE EMPRESAS DESESTRUTURADAS QUE NÃO PRESTEM SERVIÇOS ADEQUADOS E QUALIFICADOS.}

No que concerne à flexibilização das regras concernentes ao funcionamento das operadoras de planos de saúde, observa-se que a $\mathrm{RN} \mathrm{n} .^{\circ}$ 454/20 alterou a $\mathrm{RN} \mathrm{n} .^{\circ}$ 85/04, que dispõe sobre a concessão de autorização para que sejam instituídas; o que pode gerar a criação de pessoas jurídicas que não tenham a estrutura necessária para o atendimento qualificado e adequado dos usuários. Salienta-se que a RN n. ${ }^{\circ}$ 447/20 revogou o Programa de Qualificação da Saúde Suplementar ${ }^{3}$ e a RN n. ${ }^{\text {o }} 448 / 20^{4}$ implementou alterações quanto ao termo de garantia, devendo-se atentar para que os níveis de satisfatoriedade dos planos de saúde não sejam reduzidos, ferindo o equilíbrio contratual ${ }^{5}$. A participação das empresas do setor no Programa de Certificação de Boas Práticas em Atenção à Saúde requer tão somente que atinjam a pontuação mínima prevista nos respectivos manuais constantes nos anexos da RN n. $450 / 20$ - aspecto este que pode estimular a queda da qualidade-, causando prejuízos para os usuários (ALMEIDA, 2005, p. 23; ÁLVAREZ MORENO, 2015, p. 18).

No ano em curso, por meio da RN 452/20, a ANS criou o Programa de Acreditação de Operadoras de Planos Privados de Assistência à Saúde e alterou a RN no 124/06, que dispõe sobre a aplicação de penalidades face às infrações à legislação. Permitirá a autarquia que entidades se apresentem e se sejam acreditadas, objetivando "a qualificação da prestação dos serviços, induzindo a mudança no modelo de atenção", sob o fundamento de propiciar "uma melhor experiência para o beneficiário". Questiona-se como serão selecionadas e autorizadas tais instituições e se, realmente, executarão, com perspicácia e eficiência, o trabalho de avaliação das operadoras do setor, sem tenderem para a proteção do empresariado. Alerta-se que a própria agência reguladora nem sempre tem realizado a fiscalização a contento do campo que lhe compete, alegando, frequentemente, falta de estrutura. Como fará, então, para agregar, no plexo de suas atribuições, a verificação da atuação legítima e legal das acreditadoras?

\footnotetext{
${ }^{3}$ Restou revogada a RN n. ${ }^{\circ} 139 / 06$.

${ }^{4}$ Alterou a RN n ${ }^{\circ} 137$, de 14 de novembro de 2006, e a RN n ${ }^{\circ} 392$, de 9 de dezembro de 2015.

${ }^{5}$ A RN 451/20 modificou os critérios para definição do capital regulatório.
} 
Em reunião realizada em 20.03.20, ANS iniciou as discussões para a flexibilização da gestão de recursos, possibilitando que as operadoras tenham maior liberdade para movimentar os que são reservados para outros fins ou para situações excepcionais, sob a alegação de que será facilitado o investimento na ampliação de leitos e de unidades ambulatoriais em benefício dos pacientes com o novo coronavírus. A grande preocupação será o necessário acompanhamento para que a gestão destes recursos não seja desviada deste propósito, podendo gerar o posterior aumento da mensalidade (ALABART, 2016, p. 20. ARCE, 2016, p. 33). As empresas do setor serão também beneficiadas com a prorrogação de alguns prazos acerca do cumprimento de obrigações, o envio de informações e respostas a Notificações de Intermediação Preliminar (NIP) não-assistenciais, bem como os prazos de processos sancionadores e de ressarcimento ao SUS. Compreende-se que almeja facilitar o desempenho das atividades por parte das prestadoras do serviço, mas que estas benesses não lhes sirvam para afrouxar os deveres legais e as penalidades.

\subsection{A ADMISSÃO DA “TELESSAÚDE” NO CONTEXTO ESTIGMATIZADO PELA COVID-19 E OS DIREITOS DOS USUÁRIOS: A INQUESTIONÁVEL PROTEÇÃO DA QUALIDADE QUANTO AO ATENDIMENTO E À PROTEÇÃO DOS DADOS DOS CONSUMIDORES.}

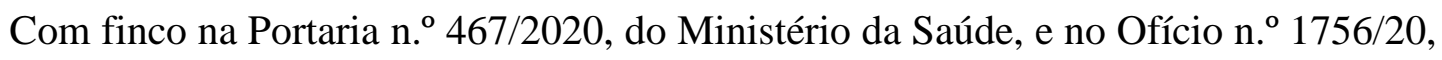
do Conselho Federal de Medicina (CFM), a ANS recomendou que as operadoras autorizarem os atendimentos médicos à distância, utilizando recursos de tecnologia da informação, durante o período de pandemia, providenciando as adequações necessárias, em suas redes. Deverão disponibilizar, aos seus clientes, canais de atendimento específicos para prestar esclarecimentos e informações sobre o coronavírus. As consultas remotas serão necessárias à disponibilização de orientações aos usuários, mas o ideal seria que avançasse mais, assegurando penalidades para as empresas que descumprissem esta regra, não se limitando a recomendá-las. Outrossim, poderia a autarquia estabelecer valores condizentes a serem pagos aos profissionais de saúde que, diante da necessidade do paciente, pudessem deslocar-se até onde este se encontra, para o examinar com acuidade.

O contexto vivenciado atraiu a atenção do mundo para as diversas possibilidades digitais disponíveis, incluindo-se a "telessaúde", que abrange a telemedicina. Em uma pesquisa realizada pela Associação Paulista de Medicina, no período de 03 a 17 de fevereiro de 2020, contando com a participação de 2.258 médicos brasileiros, de 55 especialidades, 
constatou-se que $64 \%$ dos profissionais votaram no sentido de que fosse editada uma nova regulamentação que permitisse a ampliação dos serviços. Ademais, na percepção de $90 \%$ dos entrevistados, o sistema público de saúde poderia ser beneficiado com novas ferramentas tecnológicas digitais capazes de diminuir as filas de espera por um atendimento especializado (SILVA, 2020).

A Agência Reguladora, em atenção à necessidade de isolamento social dos beneficiários de planos de saúde, adequou o Padrão de Troca de Informações na Saúde Suplementar (TISS) para melhor viabilizar a utilização do atendimento à distância, através da “telessaúde", enquanto perdurar a situação de Emergência em Saúde Pública de Importância Nacional (ESPIN). Nesta senda, ressaltou que esse é um procedimento que já apresenta cobertura obrigatória pelas operadoras, considerando que se trata de uma modalidade de consulta com profissionais de saúde, não sendo necessária inclui-la no Rol de Procedimentos e Eventos em Saúde, conforme a Nota Técnica n. ${ }^{\circ}$ 07. No entanto, para que os atendimentos sejam realizados nesta modalidade, é necessário o prévio ajuste entre as operadoras e as prestadoras de serviços através de qualquer instrumento, a exemplo da troca de e-mail ou troca de mensagem eletrônica no sítio eletrônico da operadora que permita a identificação dos serviços a serem prestados; os valores que o remunerarão e os ritos para faturamento e pagamento destes serviços.

Considerado a utilização desse recurso por outros países, no enfrentamento ao COVID-19, o Conselho Federal de Medicina (CFM), em recente decisão, no Ofício CFM n. ${ }^{\circ}$ 1756/2020 - COJUR, em caráter excepcional, enquanto durar a situação da pandemia, reconheceu a possibilidade e eticidade da utilização da telemedicina, além do disposto na Resolução CFM nº 1.643, de 26 de agosto de 2002. Os médicos poderão realizar à distância: a teleorientação, que consiste na orientação e encaminhamento dos pacientes em isolamento; o telemonitoramento, que se refere ao monitoramento ou vigência à distância de parâmetros de saúde e/ou doença; e a teleinterconsulta que se trata da troca de informações e opiniões entre profissionais da área da medicina, com o intuito de promover um auxílio diagnóstico ou terapêutico.

Em seguida, em 23 de março de 2020, entrou em vigor a Portaria n. $467 / 2020$ do Ministério da Saúde ainda foi além e incluiu o atendimento pré-clínico de suporte assistencial; a consulta; o monitoramento e o diagnóstico realizado à distância por profissionais da medicina (SILVA, 2020). Além disso, disciplinou e estabeleceu critérios para a emissão de 
receitas e atestados médicos à distância, desde que assinados com certificado digital no padrão da Infraestrutura de Chaves Públicas Brasileira - ICP-Brasil.

Além da Medicina, outras áreas de saúde passaram a admitir e "telessaúde". O Conselho Federal de Psicologia (CFP), na Resolução n. ${ }^{\circ}$ 11/2018, também regulamentou os serviços psicológicos realizados através da tecnologia da informação e da comunicação à distância, autorizando: consultas e atendimentos, processos de seleção de pessoal, supervisão técnica e aplicação de testes, desde que devidamente autorizados pelo SATEPSI e normas vigentes do referido Conselho. Na mesma linha, Conselho Federal de Fonoaudiologia (CFA) também emitiu orientação que determina, nos meses de março e abril, a teleconsulta e o telemonitoramento. Por sua vez, o Conselho Federal de Nutricionistas (CFN) deliberou, através da Resolução CFN nº 646/2020, autorizando, excepcionalmente o atendimento não presencial.

Nesta senda, ressaltou que esse é um procedimento que já apresenta cobertura obrigatória pelas operadoras, considerando que se trata de uma modalidade de consulta com profissionais de saúde, não sendo necessária incluí-la no Rol de Procedimentos e Eventos em Saúde, conforme a Nota Técnica n. ${ }^{\circ}$ 07. No entanto, para que os atendimentos sejam realizados nesta modalidade, é necessário o prévio ajuste entre as operadoras e as prestadoras de serviços através de qualquer instrumento, a exemplo da troca de e-mail ou troca de mensagem eletrônica no sítio eletrônico da operadora que permita a identificação dos serviços a serem prestados; os valores que o remunerarão e os ritos para faturamento e pagamento destes serviços.

No dia 15 de abril de 2020, foi sancionada a Lei n. ${ }^{\circ}$ 13.989/20, com vetos. De acordo com a nova legislação, encontra-se autorizado, em caráter emergencial, o uso da telemedicina, enquanto durar a crise ocasionada pelo coronavírus. A telemedicina é conceituada, no art. $3^{\circ}$, como "o exercício da medicina mediado por tecnologias para fins de assistência, pesquisa, prevenção de doenças e lesões e promoção de saúde". Desse modo, o médico deverá informar ao paciente todas as limitações inerentes ao uso da telemedicina, tendo em vista a impossibilidade de realização de exame físico durante a consulta (art. $4^{\circ}$ ). Ademais, a prestação de serviço de telemedicina seguirá os padrões normativos e éticos usuais do atendimento presencial, inclusive em relação à contraprestação financeira pelo serviço prestado, não cabendo ao poder público custear ou pagar por tais atividades quando não for exclusivamente serviço prestado ao Sistema Único de Saúde (SUS) (art. $5^{\circ}$ ). 
No entanto, dois dispositivos foram vetados. O primeiro transferia para o Conselho Federal de Medicina a regulamentação da telemedicina após o fim da pandemia, porém o presidente alegou que a citada regulamentação deve ser realizada por uma nova legislação. $\mathrm{O}$ segundo conferia validade às receitas médicas virtuais, desde que apresentassem assinatura com certificação digital ou apenas digitalizada. Entretanto, o presidente asseverou que essa medida poderia gerar risco sanitário à população, por facilitar a adulteração, ao equiparar a assinatura que utiliza criptografia, dispondo de validade jurídica à digitalizada, fácil de ser adulterada. Além disso, fez menção à possibilidade de aumento indiscriminado na venda de medicamentos controlados.

No que concerne à proteção de dados, observa-se que o Senado aprovou que a vigência da Lei Geral de Proteção de Dados (LGPD) seja postergada para janeiro de 2021, justamente em decorrência da pandemia do coronavírus. No entanto, as empresas de tecnologia e as prestadoras de serviços médicos, responsáveis por desenvolver softwares e plataformas digitais com soluções voltadas à teletriagem, teleorientação, telelaudos, teleconsultas, seguem com o dever de respeitar o Código de Defesa do Consumidor, o Código de Ética Médica e as resoluções pertinentes do Conselho Federal de Medicina.

Destarte, necessitam adotar as cautelas necessárias para que as informações, obtidas através de uma consulta realizada através da Telemedicina, sejam protegidas, evitando o acesso de pessoas não autorizadas. $O$ dever de sigilo profissional se estende às equipes envolvidas no atendimento, a exemplo dos enfermeiros, nutricionistas e farmacêuticos; outrossim, outras pessoas, além dos profissionais de saúde, não estão autorizadas a acessar o prontuário sem o consentimento do paciente. Neste sentido, pode adotar recursos detecção de vulnerabilidades de hardwares e softwares, efetuar backups periódicos e realizar controles de acessos (com travas especiais nas portas e biometria, firewall, antimalware, dupla criptografia para banco de dados).

2.4 A ALTERAÇÃO DOS PRAZOS PARA O ATENDIMENTO DOS USUÁRIOS DOS PLANOS DE SAÚDE SOB A ALEGAÇÃO DA PRIORIDADE AOS CASOS ENVOLVENDO A MOLÉSTIA COVID-19: SUSPENSÕES E AMPLIAÇÕES QUE NÃO PODEM OBLITERAR O NECESSÁRIO DIAGNÓSTICO E O TRATAMENTO DOS CONSUMIDORES. 
A Agência Nacional de Saúde Suplementar, diante da crise causada pela pandemia e da necessidade de reduzir a sobrecarga das unidades de saúde, prorrogou, em caráter excepcional, os prazos máximos de atendimento previstos na Resolução n. ${ }^{\circ} 259$ para a realização de consultas, exames, terapias e cirurgias que não sejam urgentes. Sob o fundamento de que as operadoras devem priorizar o atendimento aos pacientes portadores do novo coronavírus, a ANS ampliou e suspendeu determinados correlatos à concretização de consultas, tratamentos e procedimentos, exceto os casos de urgência e emergência que recepção imediata do paciente.

Terão atendimento nos prazos normais os casos em que o médico assistente justifique por meio de atestado, bem como os tratamentos que não podem ser interrompidos ou adiados por colocarem em risco a vida do paciente. Nestes, estão incluídos o pré-natal, parto e puerpério; as doenças crônicas; os tratamentos continuados; as revisões pósoperatórias; diagnóstico e terapias em oncologia e psiquiatria. Restaram obliterados os Atendimento em regime de hospital-dia e em regime de internação eletiva. No entanto, devem ser mantidos aqueles referentes aos casos em que os tratamentos não podem ser interrompidos ou adiados, por oferecer perigo à vida do paciente, tais como a quimioterapia e a hemodiálise, aqueles relacionados à gravidez, à doenças crônicas, às revisões pós-operatórias, aos diagnósticos e terapias em oncologia, à psiquiatria, bem como aos atendimentos de urgência e emergência. Neste sentido, tais tratamentos devem obedecer aos prazos da Resolução RN 259/2011 da ANS, indicados acima.

No que concerne às consultas básicas, para pediatria, clínica médica, cirurgia geral, ginecologia e obstetrícia, o paciente deverá aguardar 14 dias e não mais 7 , como anteriormente; já para as demais especialidades, terá que esperar 28 dias e não mais 14. Atendimentos e sessões com fonoaudiólogo, nutricionista, psicólogo, terapia ocupacional e fisioterapeuta pressupõem, agora, marcação em 20 dias e não 10. Para as consultas e procedimentos realizados em consultório/clínica com cirurgião, estabeleceu-se o prazo 14 dias, sendo que antes eram 7. Os serviços de diagnóstico por laboratório de análises clínicas tiveram o prazo duplicado de 3 para 6 dias, do mesmo modo os demais serviços de diagnóstico e terapia em regime ambulatorial, ou seja, de 10 para 20 dias. Por fim, os Procedimentos de alta complexidade (PAC) teve a designação estendidas de 21 para 42 dias. Considerando que o coronavírus pode causar uma infecção respiratória aguda, levando sujeitos, inclusive, à óbito, a depender do caso concreto, é preciso analisar se tais prazos têm 
condições de serem cumpridos sem exporem a vida do consumidor a risco, caso contrário, o atendimento deve ser imediato.

\subsection{O REAJUSTE DAS MENSALIDADES DOS CONTRATOS DE ASSISTÊNCIA SUPLEMENTAR À SAÚDE NA VIGÊNCIA DA PANDEMIA COVID-19: A QUESTÃO DO EQUILÍBRIO CONTRATUAL.}

Conforme informações prestadas pelo IDEC, as mensalidades não devem ser reajustadas no ano de 2020, considerando que devem ser analisados os atendimentos realizados nos anos anteriores, quais sejam: 2018 e 2019. Neste sentido, o Instituto oficiou o Ministério Público Federal e dos demais Estados mais afetados, solicitando a abertura da investigação dos preços, bem como oficiou à Agência Nacional de Saúde Suplementar, para que realizasse um estudo do impacto das medidas de enfrentamento à COVID-19. No entanto, é possível que as operadoras solicitem a aplicação do denominado reajuste por sinistralidade, que é um aumento imposto sob a alegação de que os consumidores utilizaram mais o plano do que o previsto em determinado período, de modo que o número de procedimentos e/ou atendimentos cobertos ultrapassou o esperado.

Constatam-se decisões judiciais sobre o assunto, em que se admite o reajuste por sinistralidade, desde que seja previamente comprovado o desequilíbrio contratual, devendo ser restituídas as diferenças devidas, a exemplo do provimento jurisdicional concedida pelo Tribunal de Justiça de São Paulo, nos autos da Apelação n. ${ }^{\circ} 10047856320148260562$. Contudo, tendo em vista que cerca de $\mathrm{R} \$ 15$ bilhões de reais de fundos foram destinados a garantir o atendimento em situações emergenciais, que os planos de saúde são obrigados a recolher e utilizar para atendimento dos usuário, apenas em situações completamente extremas, tal majoração por sinistralidade deve ser admitida.

Define-se a sinistralidade como a ocorrência do crescimento do número de eventos resultante do uso intenso dos planos de saúde pelos usuários, como verbi gratia: consultas, cirurgias, exames, doenças, tratamentos, procedimentos diversos, etc., levando-se em consideração o total de contratos celebrados. Alegam as operadoras de planos de saúde que elevar a utilização dos serviços previstos no instrumento contratual celebrado, e consequentemente a realização dos tratamentos necessários, acarretam maiores despesas para as empresas do setor que disponham de estrutura própria e, principalmente, para as que mantenham vínculos com rede conveniada ou referenciada. O fundamento, portanto, do 
aumento por sinistralidade consiste na maior utilização do plano de saúde pelo consumidor e na quantidade de serviços executados em benefício deste.

Examinando-se o teor da Lei . $^{\circ}$ 9.656/98, não se vislumbra a presença de normas que autorizem a permanência dos aumentos com base na sinistralidade. O artigo 16, inciso XI da lei em tela, exige que as operadoras de planos de saúde estabeleçam, no ato da contratação, "os critérios de reajuste e revisão das contraprestações pecuniárias" (BOTTESINI; MACHADO, 2015; GREGORI, 2011; SILVA, 2009), não tratando, de modo preciso, do problema relativo à sinistralidade. A análise global do diploma legal demonstra que, apenas, os reajustes anuais e os embasados nas faixas etárias previstas são chancelados. Aduz Clayton Maranhão que "é abusivo o repasse dos custos da má administração aos usuários mediante o referido aumento por sinistralidade, sendo ilegal qualquer disposição nesse sentido" (MARANHÃO, 2003, p. 230).

Visando dirimir os questionamentos e as dúvidas existentes sobre a possibilidade da prática dos aumentos fundamentados na sinistralidade, em 26 de junho de 2000, a Agência Nacional de Saúde Suplementar editou a Resolução de Diretoria Colegiada (RDC) n. ${ }^{\circ}$ 27/00, prevendo a revisão técnica destinada à promoção do reequilíbrio econômico-financeiro das operadoras. Desta maneira, restou comprovada a inadmissibilidade dos aumentos com base na sinistralidade, podendo as empresas, que sofrerem afetação da sua estrutura operacional, em razão do alto índice de utilização dos usuários, solicitarem uma reavaliação da situação econômica e financeira, por meio de procedimento próprio e não, unilateralmente, impor o aumento. Realizada a dita revisão, o resultado, porém, pode ser a autorização para aumento da mensalidade do plano de saúde ou a revisão da rede assistencial; o que ocasionará um sacrifício para o consumidor que já arca com as majorações anuais.

Ao contratar um plano de saúde, o consumidor tem uma expectativa de que possa dispor dos serviços previstos na proposta sem que ocorram modificações unilaterais e injustificadas nas contraprestações pecuniárias. Diante do quadro pandêmico vislumbrado, caso determinada operadora venha a requerer a revisão técnica, destaca-se, mais uma vez, a importância de que o cálculo atuarial seja completo e real, para justificar a imposição do aumento. Na realidade, não se almeja que as operadoras de planos de saúde sejam prejudicadas quanto à esperada rentabilidade e lucratividade, mas que a eventual alegação de desequilíbrio seja averiguada, mediante critérios severos, pelo ente regulador, admitindo-se, somente em casos extremamente necessários, majorações das mensalidades previstas. 


\section{O PRINCÍPIO DA SOLIDARIEDADE NOS CONTRATOS DE ASSISTÊNCIA SUPLEMENTAR À SAÚDE: A CONFIGURAÇÃO DE FUNDOS MÚTUOS.}

Os planos se caracterizam pela necessária constituição de um fundo mútuo, ou seja, pela formação de uma massa financeira que servirá de lastro para que as empresas gestoras atendam às demandas dos usuários. Todos os consumidores devem, mensalmente, efetivar o pagamento de contraprestações, mas a utilização dos serviços disponibilizados dependerá da necessidade de cada usuário, permitindo que as operadoras e seguradoras angariem recursos financeiros suficientes para comporem fundos que servirão para a garantia do atendimento de todos os contratantes (FERNANDES NETO, 2002, p. 21).

A saúde pode ser analisada sob a ótica individual, pois qualquer indivíduo tem o direito de contratar empresas que se predisponham à efetivação da assistência privada, mas como surgem sempre relações estandardizadas com uma multiplicidade de usuários, há a possibilidade de tutela coletiva. A dimensão coletiva dos conflitos advindos das relações travadas entre as operadoras de planos de saúde com os consumidores, portanto, pode ser constatada sob dois aspectos: a constituição de fundos mútuos e a presença de uma multiplicidade de usuários que aderem às modalidades ofertadas no mercado. Na medida em que são formados aglomerados financeiros para servirem de suporte para a prestação da assistência à saúde dos indivíduos, há uma interligação entre os interesses de todos no sentido de que o gerenciamento resulte de ações responsáveis e conscientes, permitindo um equilíbrio da carteira contratual.

Os aspectos singulares que caracterizam os contratos de planos e seguros de saúde exigem uma atuação fiscalizatória do Poder Público. A prestação de serviços de saúde por particulares apenas ocorre mediante a chancela do aparato estatal e exige um acompanhamento frequente por parte dos órgãos fiscalizatórios. A importância do objeto contratual, a presença de uma multiplicidade de consumidores, a extensão temporal da relação contratual e ainda a submissão dos consumidores a propostas previamente elaboradas ao sabor dos interesses das empresas são peculiaridades que suscitam uma atenção redobrada do Estado (LORENZETTI, 2003, p. 326).

\section{CONCLUSÃO}


As consequências negativas geradas pela pandemia COVID-19 para o campo da saúde suplementar são inquestionáveis, reverberando na estrutura assistencial referente aos contratos firmados nesta seara. Por se configurarem vínculos jurídicos existenciais e duradouros, visto que tratam do bem maior - a vida - e não são estabelecidos para vigerem por exíguo espaço temporal, exigem uma fiscalização quanto ao respeito dos direitos basilares dos usuários. A despeito da proeminência destes serviços para a manutenção do estado vital dos seres humanos, não se tem vislumbrado, até o presente momento, uma atuação profícua da Agência Nacional de Saúde Suplementar para se observar se as operadoras do setor têm efetivamente zelado pela qualidade dos atendimentos e pelo equilíbrio contratual.

Restou estabelecida a obrigatória cobertura do exame para diagnosticar a referida moléstia infecciosa e admitiu-se a "telessaúde", possibilitando o atendimento remoto dos pacientes, mas poderia a autarquia reguladora progredir na garantia do deslocamento de profissionais de saúde para o local onde se encontra o paciente, quando necessário, assegurando-lhe o pagamento adequado. Sucedeu-se à alteração dos prazos para o atendimento dos usuários dos planos de saúde sob o fundamento da imperiosa prioridade aos casos acarretados pela pandemia, sendo que dúvidas não pairam sobre a sobressalência destes. Entrementes, as suspensões e as dilatações não podem obliterar o necessário diagnóstico e o tratamento dos usuários, não podendo as empresas se utilizarem desta justificativa para não proceder às diligências cruciais à imprescindível verificação das necessidades dos pacientes. Não se deve olvidar das regras que disciplinam a responsabilidade dos nosocômios e de demais estabelecimentos de saúde, bem como dos profissionais do setor.

Conquanto se compreenda que a flexibilização das regras para a instituição de operadoras de planos de saúde pode contribuir para a concorrência setorial e a ampliação das oportunidades de seleção pelos consumidores, não podem emergir pessoas jurídicas desestruturadas que não prestem serviços adequados e qualificados. Cuidadosa análise deverá ser realizada quanto à utilização de recursos reservados pelas empresas, com o desiderato de que não sejam desviados da finalidade essencial. O eventual reajuste das mensalidades dos contratos de assistência suplementar à saúde na vigência da pandemia exige cálculo atuarial seriamente averiguado e somente justificar-se-á se, evidentemente, primar pelo equilíbrio contratual e pela solidariedade perante a configuração de fundos mútuos.

\section{REFERÊNCIAS}


ALABART, Silvia Díaz. Introducción: la contratación com consumidores. In: ALABART, Silvia Díaz (Coord.) Manual de Derecho de Consumo. Madrid: Editorial Reus, S.A, 2016.

ALMEIDA, Carlos Ferreira de. Os direitos dos consumidores. Coimbra: Almedina, 2005.

ÁLVAREZ MORENO, Maria Teresa. La protección jurídica del consumidor en la contratación en general (normas interpretativas y pactos al respecto). Madrid: Reus, 2015.

ARCE, Alicia de León (Dir.). Derecho de los Consumidores y Usuarios. 3. ed. Madrid: Tirant lo Blanch, 2016, 2 Tomos.

BOTTESINI, Maury; MACHADO, Mauro Conti. Lei dos Planos e Seguros de Saúde Comentada. 3. ed. São Paulo: RT, 2015.

BENJAMIN, Antônio Herman de Vasconcellos et al. Código Brasileiro de Defesa do Consumidor. 10. ed. rev. atual. e reform. Rio de Janeiro: Forense, 2017, volume I, p. 89.

FERNANDES NETO, Antônio Joaquim. Planos de Saúde e Direito do Consumidor. Belo Horizonte: Del Rey, 2002.

GHERSI. Carlos Alberto.; WEINGARTEN, Celia.; IPPOLITO, Silvia C. Contrato de medicina prepaga. 2. ed. atual. e ampl. Buenos Aires: Astrea, 1999.

GREGORI, Maria Stella. Planos de Saúde - a Ótica de Proteção do Consumidor. 3. ed. São Paulo: RT, 2011.

HERRERA, Enrique. Práctica metodológica de la investigación jurídica. Buenos Aires: Astrea, 1998.

LORENZETTI, Ricardo Luis. Fundamentos de Direito Privado. Trad. Vera Maria Jacob Fradera. São Paulo: Revista dos Tribunais, 1998.

2000, t. I. . Tratado de los contratos. Buenos Aires: Rubinzal-Culzoni, 19992003. . Consumidores. Buenos Aires: Rubinzal-Culzoni Editores,

MACEDO JÚNIOR, Ronaldo Porto. Contratos Relacionais e Defesa do Consumidor, São Paulo: Max Limonad, 1998.

MARANHÃO, Clayton. Tutela Jurisdicional do Direito à Saúde (Arts. 83 e 84, CDC). Coleção Temas Atuais de Direito Processual Civil Volume 07. Editora Revista dos Tribunais, 2003.

MARQUES, Cláudia Lima. Prefácio da obra Plano de Saúde e Direito do Consumidor, de Antonio Joaquim Fernandes Neto, Minas Gerais: Del Rey, 2002.

. A abusividade nos contratos de assistência à saúde e de assistência médica no Brasil. Revista da Associação dos Juízes do Rio Grande do Sul, Porto Alegre, v. 22, n. 64, p. 34-77, jul. 1995. 
Defesa do Consumidor, São Paulo: RT, 2002.

Revista dos Tribunais, 2019.

. Contratos no Código de Defesa do Consumidor. 9. ed. São Paulo:

MIRAGEM, Bruno. Curso de direito do consumidor. 8. ed. São Paulo: RT, 2019.

. Nota relativa à pandemia de coronavírus e suas repercussões sobre os contratos e a responsabilidade civil. São Paulo, Revista de Direito do Consumidor, vol. 1015/2020, p. 1-9, maio 2020.

SCAFF, Fernando Campos. Direito à Saúde no Âmbito Privado. São Paulo: Saraiva, 2010.

SCHULMAN, Gabriel. Planos de Saúde. Rio de Janeiro: Renovar, 2009.

SILVA, Joseane Suzart Lopes da. Planos de Saúde e Boa-Fé Objetiva: uma análise crítica dos reajustes abusivos. 2. ed. Salvador-BA: Jus Podiuvm, 2009.

. O Projeto de Lei 7.419/06, a reestruturação da assistência suplementar à saúde no Brasil e a necessária atuação do Sistema Nacional de Proteção ao Consumidor (SNDC). Revista de Direito do Consumidor, São Paulo, ano 27, n. 116, mar.abr.2018, p. 217-260.

Como proteger o consumidor quanto aos bens essenciais na COVID-19. São Paulo, Revista Consultor Jurídico, Coluna Direito Civil Atual, 11 de abril de 2020.

SILVA, Ana Clara Suzart Lopes da. A Telessaúde diante da Pandemia COVID-19. Disponível em: https://anaclarasuzart.com.br/a-telessaude-diante-da-pandemia-covid-19/. Acesso em 13 abr. 2020.

Os Impactos do Coronavírus na Saúde Privada. Disponível em: https://anaclarasuzart.com.br/os-impactos-do-coronavirus-na-saude-privada/. Acesso em 13 abr. 2020.

- Os direitos dos recém-nascidos quanto aos planos de saúde. Disponível em: https://anaclarasuzart.com.br/os-direitos-dos-recem-nascidosquanto-aos-planos-de-saude/. Acesso em 04 abr. 2020.

TRETTEL, Daniela Batalha. Planos de Saúde - na Visão do STJ e do STF. São Paulo: Verbatim, 2009.

WITKER, Jorge. Como elaborar una tesis en derecho: pautas metodológicas y técnicas para el estudiante o investigador del derecho. Madrid: Civitas, 1985. 